\title{
Comunicação e cultura na telenovela juvenil: naturalismo, nação e contaminação de temas em Malhação: Vidas Brasileiras
}

\section{João Paulo Hergesel}

Professor permanente do Programa de Pós-Graduação em Linguagens, Mídia e Arte da Pontifícia Universidade Católica de Campinas (PUC-Campinas). Doutor em Comunicação (UAM), mestre em Comunicação e Cultura (Uniso) e licenciado em Letras (Uniso). Membro do grupo de pesquisa Entre(dis)cursos: sujeito e língua(gens).

E-mail: joao.hergesel@puc-campinas.edu.br

Paula Regina da Silva Ferreira

Doutoranda em Comunicação (UAM), mestra em Comunicaşão (UAM), especialista em Cinema, Vídeo e Fotografia: criação em multimeios (UAM), graduada em Comunicação Social com habilitação em Jornalismo (UMESP).

E-mail: paulapazdodharma@gmail.com

Resumo: Malhação: Vidas Brasileiras destacou-se pelos temas de cunho social abordados. O objetivo deste trabalho é compreender suas dimensões comunicacionais e os desdobramentos culturais que podem impactar na fruição dos jovens telespectadores, a partir da análise das narrativas culturais da trama. A metodologia adotada mescla os métodos observativo e interpretativo, partindo das descrições de algumas cenas do produto e cotejando-as com as teorias e discussões a respeito dos fenômenos. O corpo teórico que respalda essas leituras reúne Maria Immacolata Vassalo de Lopes (2009; 2014), Elizabeth Rondelli (1997), entre outros autores que versam sobre a telenovela e sua relação com os entrelaçamentos socioculturais. $\mathrm{O}$ resultado apontou, dentre outros
Abstract: Malhação: Vidas Brasileiras was popular due to the social issues it addressed. Thus, this paper analyzes its communication dimensions and the cultural developments that can impact on the fruition of young viewers, based on the analysis of the cultural narratives of the plot. The adopted methodology merges the observation and interpretation methods, starting with the descriptions of some scenes of the product and comparing them to theories and discussions about its relevant phenomena. The theoretical framework that supports these readings includes Maria Immacolata Vassalo de Lopes (2009, 2014), Elizabeth Rondelli (1997), among other authors who talk about the telenovela and its relation to sociocultural interlacings. Among
Recebido: 02/05/2019

Aprovado: 13/08/2019 
aspectos, que a geração dos videogames e das redes sociais tem um produto televisivo à sua disposição, com elementos de seu contexto sociocultural: uma tradicional telenovela brasileira, fórmula consagrada no imaginário e na cultura.

Palavras-chave: audiovisual; televisão; ficção seriada; telenovela; narrativa juvenil. the results the generation of video games and social networks was shown to have a television product at its disposal, with elements of its sociocultural context: the traditional Brazilian telenovela, a formula consecrated in its imaginary and culture.

Keywords: audiovisual; television; serial fiction; telenovela; juvenile narrative.

\section{INTRODUÇÃO}

Malhação (Rede Globo, 1995-presente) é uma ficção seriada desenvolvida em forma similar à de soap opera, isto é, obra televisual produzida em forma de capítulos sequenciais, por tempo indeterminado - sem data prevista para terminar -, sobre um mesmo tema, com prováveis trocas de personagens ao longo da narrativa. No caso de Malhação, as trocas de personagens trazem consigo trocas de enredos e de intrigas, estabelecendo uma nova narrativa dentro da temática principal: o universo adolescente.

Essa estrutura faz com que Malhação se comporte como um conglomerado de telenovelas distintas, porém unidas pela semelhança das ações. Em sua $26^{\circ}$ temporada, foi apresentada a telenovela juvenil Malhação: Vidas Brasileiras (autoria de Paula Moretzsohn, 2018-2019), que se destacou devido aos temas de cunho social que abordou ao longo da narrativa, incluindo a discussão de assuntos que são socialmente considerados como tabus.

Com o título traduzido para Young Hearts - Brazilian lives, a obra foi finalista do International Format Awards 2019, na categoria Best Scripted Format, perdendo para Insoupçonnable (The Fall), da emissora francesa TF1 ${ }^{1}$.

1.THE INTERNATIONAL Format Awards. C21Media, Londres, 2019. Disponível em: https://www.c21media. net/the-international-format-awards-2019/. Acesso em: $1^{\circ}$ maio 2019.

2.LOPES, Maria Immacolata Vassalo de. Telenovela como recurso comunicativo. MATRIZes, São Paulo, v. 3, n. 1, p. 21-47, 2009 Disponível em: http://www. revistas.usp.br/matrizes/ article/view/38239. Acesso em: $1^{\circ}$ maio 2019

3.MARTÍN-BARBERO, Jesús. Latin America: cultures in the communication media. Journal of Communication, Oxford v. 43, n. 2 p. 18-30, 1993, p. 23.

4.MARTÍN-BARBERO, op cit., p. 23.
Portanto, devido às temáticas socioculturais e à repercussão da telenovela em âmbito internacional, o presente artigo analisa suas dimensões comunicacionais e os desdobramentos culturais que podem impactar na fruição dos jovens telespectadores, por meio de análises das narrativas culturais da trama.

Por estar pautada em discutir diversas questões sociais referentes às vivências experimentadas tanto pelos adolescentes quanto pelos adultos que aparecem na trama, Malhação: Vidas Brasileiras apresenta interessantes expedientes para pensarmos em seu "recurso comunicativo"² e nas repercussões no âmbito cultural que essas discussões geram para os telespectadores, principalmente para os mais jovens. Afinal, "a telenovela, como texto, é um diálogo no qual atores,

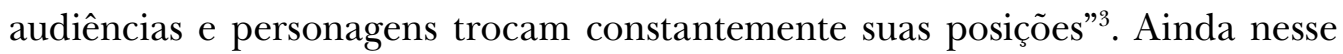
raciocínio, "esta troca refere-se à confusão entre o que um personagem está experimentando e o que o telespectador sente, uma experiência estética da identidade que é aberta e conta com as expectativas e reações do público"*

Devido aos temas de que a telenovela trata, percebe-se que o telespectador juvenil pode exercer a condição psicológica de identificação e de projeção 
com os personagens da trama, isto é, compreender seu próprio universo e sua identidade no mundo a partir das reflexões que a narrativa propõe e das discussões geradas fora do âmbito ficcional. É sabido que os assuntos discutidos nas telenovelas repercutem na sociedade: fala-se da novela no dia a dia, do que aconteceu na história narrada, do destino dos personagens e, principalmente, dos temas abordados. Há, portanto, uma "contaminação" entre aquilo que é do âmbito privado com aquilo que é da esfera pública, com aquilo que aparentemente é um fato apenas na ficção, mas que pode vir a ser fato na realidade dos telespectadores.

Para dar conta das proposições deste trabalho, utiliza-se o método observativo e interpretativo, partindo das descrições de algumas cenas do produto e questionando-as a partir das teorias e discussões a respeito dos fenômenos que sua fruição pode propiciar. O corpo teórico que respalda essas leituras, por sua vez, reúne Maria Immacolata Vassalo de Lopes ${ }^{5,6}$, Elizabeth Rondelli ${ }^{7}$, entre outros autores que versam sobre a telenovela e sua relação com os entrelaçamentos socioculturais.

\section{SOBRE A TELENOVELA}

Malhação: Vidas Brasileiras é uma adaptação da soap opera canadense 30 Vies (de Fabienne Larouche para a Ici Radio-Canada Télé), exibida entre os anos de 2011 e 2016. Tendo concorrido três vezes ao Emmy Internacional de novelas, 30 Vies durou 11 temporadas, com 660 episódios ao todo, e narrava a história de uma professora do Ensino Médio que constantemente ajudava seus alunos a resolver problemas típicos da adolescência ou experiências mais complexas, como vício em drogas, envolvimento com gangues, xenofobia, automutilação, agressão doméstica, depressão etc.

A versão brasileira tem como protagonista a idealista e entusiasmada professora Gabriela Fortes (Camila Morgado), que leciona Língua Portuguesa e Literatura no colégio particular Sapiência, localizado no bairro de Botafogo, no Rio de Janeiro. Gabriela sonha há anos em poder contribuir com a educação de jovens carentes para proporcionar um melhor direcionamento para suas vidas e, consequentemente, um futuro profissional digno para aqueles que não têm fácil acesso a uma educação de qualidade.

Já no primeiro capítulo, Gabriela se depara com o dilema entre continuar lecionando no colégio particular ou se aventurar em participar do projeto da ONG Percurso, que direciona jovens de baixa renda para estudar em bons colégios particulares, por meio de bolsas de estudos fornecidas pelas escolas conveniadas. Eventualmente, a professora consegue firmar uma parceria entre a referida ONG e o colégio onde leciona há tantos anos e é considerada uma professora indispensável, também sendo muito querida pelos alunos.

Além disso, nesse primeiro capítulo, ela presencia a cena de um arrastão sendo realizado por adolescentes durante o momento de intenso
5.LOPES, 2009, op. cit.

6.LOPES, Maria Immacolata Vassalo de. Memória e identidade na telenovela brasileira. In: ENCONTRO ANUAL DA COMPÓS, 23., Universidade Federal do Pará, Curitiba, 2014 Anais [...]. Brasília: Compós, 2014. Disponível em: http://compos.org.br/encontro2014/anais/Docs/ GT12_ESTUDOS_DE_TELEVISAO/templatexxiiicompos_2278-1_2246.pdf. Acesso em: $1^{\circ}$ maio 2019

7.RONDELLI, Elizabeth. Realidade e ficção no discurso televisivo. Letras Curitiba, 11. 48, p. 149 207, 1997. Disponível em: https://revistas.ufpr. br/letras/article/ view/19016/12326. Acesso em: $1^{\circ}$ maio 2019. 
congestionamento em um túnel. Nesse instante, ela se dá conta de que aqueles jovens têm a mesma faixa etária que seus alunos no colégio particular, e isso parece realimentar seu desejo de ajudar aqueles que estão à margem do acesso à educação de qualidade e, portanto, predispostos a caírem na criminalidade.

A vinda dos novos alunos bolsistas para o Colégio Sapiência impacta a rotina da escola e faz com que diversas questões sociais novas sejam abordadas na trama devido às experiências vivenciadas por esses alunos tanto no ambiente escolar como na vida pessoal. A obra, a cada quinze dias, evidencia um novo personagem e discute seus problemas, anseios e sentimentos, sempre respaldada pela ajuda da professora que parece estar não só atenta aos adolescentes em relação aos estudos, mas também preocupada com o bem-estar deles na vida pessoal, exercendo algumas vezes o papel de amiga, além do de professora.

A parceria do colégio com a ONG traz um antigo amor mal resolvido de volta à vida da professora Gabriela, e esse evento acabará por abalar o fragilizado casamento dela. Devido ao fato de se dedicar sobremaneira ao trabalho, a família se sente, por vezes, negligenciada. Gabriela é casada com Paulo (Felipe Rocha) e é mãe de três filhos: os gêmeos adolescentes Flora (Jeniffer Oliveira) e Alex (Daniel Rangel) e a pequena Mel (Maria Rita).

Entre os dilemas da vida pessoal e do trabalho, constantemente preocupada com seus alunos e suas vivências, talvez culpada por não dar a devida atenção aos filhos e ao marido, Gabriela protagoniza a figura de uma mulher humanitária, sensível, apaixonada e forte, mas que também titubeia perante suas próprias fragilidades.

Diversas temáticas são abordadas ao longo dos capítulos, como desemprego, uso de drogas, intolerância religiosa, assédio sexual, machismo, gravidez na adolescência, gordofobia, idealização do corpo, anorexia, criminalidade, agressão, tráfico de drogas, alcoolismo, adoção, entre outros temas sociais. Esse aspecto engloba a referida obra no segmento das telenovelas naturalistas.

\section{SOBRE O NATURALISMO NAS TELENOVELAS}

Lopes $^{8}$ divide as telenovelas brasileiras em três fases, partindo de um modelo de periodização, no qual especifica que entre os anos de 1950 e 1967, observa-se a fase sentimental das telenovelas brasileiras; para o período que compreende os anos entre 1968 e 1990, a autora observa tratar-se de uma fase realista e, finalmente, a partir da década de 1990, as telenovelas passam a ser naturalistas. Percebe-se que, ao priorizar o estilo naturalista, a telenovela passa a evidenciar mais os temas sociais.

Segundo a autora, ancorada nos estudos de Ismail Xavier, há uma sugestão de que "ao dar ênfase a este último estilo de linguagem, a telenovela passa a tratar os temas com uma forte representação "naturalista', em que o discurso é identificado pela própria realidade/verdade" . Isso "faz com que ela ganhe verossimilhança, credibilidade e legitimidade enquanto ação pedagógica”" ${ }^{10}$. 
De origem melodramática, a telenovela brasileira ainda conserva inúmeras característica do gênero - como o enfoque em temas que expõem conceitos de cunho moral ou ético; o maniqueísmo representado pela luta entre o bem e o mal; a discussão sobre os dogmas morais; a representação dos dramas afetivos mal resolvidos; a presença de personagens peculiares, estereotipados e facilmente reconhecíveis etc. Esse é um fenômeno que parece se sobressair no segmento infantojuvenil.

Um exemplo disso é o SBT, emissora reconhecida pelas telenovelas infantojuvenis que vem produzindo desde 2012, cujas obras de ficção seriada "mantêm, ainda que de forma atualizada, as tendências que vigoravam nas radionovelas cubanas do século XX"11. As temáticas de cunho social, por sua vez, aparecem "de maneira camuflada, como subtramas didáticas, colocadas de modo a não desviar a atenção dos aspectos sentimentais e de entretenimento que prevalecem nas narrativas"12.

A efeito de sintetizar essa comparação, as telenovelas infantojuvenis do SBT seguem a clássica "estrutura de melodrama latino-americano, com referências a símbolos nacionais, à identidade cultural do contexto em que foi produzida, com forte impacto musical e imagens emblemáticas que antecipam acontecimentos"13. Já no caso da produção juvenil da Rede Globo, em especial Malhação: Vidas Brasileiras, observa-se que o sentimentalismo melodramático foi perdendo terreno para as narrativas mais preocupadas com fenômenos sociais e focadas em retratar os aspectos culturais da atualidade, dando ênfase às discussões dos temas sociais que também estão em destaque em outros meios de comunicação.

Segundo Lopes ${ }^{14}$, é a partir do entendimento dessa raiz melodramática das telenovelas que podemos compreender a fase mais naturalista desse tipo de ficção e, portanto, interpretar seu recurso comunicativo, tanto que ela afirma que:

abordar a novela como recurso comunicativo é identificá-la como narrativa na qual dispositivos discursivos naturalistas ou documentarizantes passam a ser deliberadamente explicitados e combinados com diversificações da matriz melodramática da telenovela. Esses dispositivos se tornaram cada vez mais frequentes e têm se alargado para o conjunto das subtramas que caracterizam as telenovelas, além de passarem a ser conhecidos como merchandising social ${ }^{15}$.

Malhação, ao longo dos anos em que está no ar na Rede Globo, parece ter se aprofundado em explorar as questões sociais. A telenovela/temporada intitulada Malhação: Vidas Brasileiras foi inclusive anunciada dando destaque a esse aspecto: os quatro teasers de lançamento mostram os personagens Érico, Talíssia, Úrsula e Tito a partir do conceito "como me mostro não é como me veem”, lema repetido por todos eles nos quatro filmes, além da linguagem descontraída e da estética incrementada pelas formas gráficas.

No comercial de lançamento, veiculado um mês antes da estreia, a professora Gabriela aparece relatando que ela "vê mais que alunos" e deixando evidente que esses alunos enfrentarão problemas complexos ao longo da narrativa. Com o slogan "Em cada vida, várias histórias", a propaganda reforça a ideia
11.HERGESEL, João Paulo; FERRARAZ, Rogério. Melodrama infantojuvenil na televisão brasileira: análise estilística de Carrossel (SBT, 2012-2013). Conexão - Comunicação e Cultura, Caxias do Sul, v. 16, n. 31, p. 201-222, 2017, p. 218.

12.Idem.

13.HERGESEL, João Paulo. Carrossel de sentimentos: melodrama na telenovela do SBT. Fronteiras: estudos midiáticos, São Leopoldo, v. 19, p. 72-82, 2017 Disponivel em: http://www. revistas.unisinos.br/index. $\mathrm{php} /$ fronteiras/article/ view/12444. Acesso em: $1^{\circ}$ out. 2020, p. 81.

14.LOPES, 2014, op. cit. 15.Ibidem, p. 5. 
de que os telespectadores podem se preparar para acompanhar diversas discussões importantes sobre a vida dos adultos e, principalmente, dos adolescentes da telenovela.

\section{SOBRE OS TEMAS DA NAÇÃO NA TELENOVELA}

No primeiro capítulo, exibido em 7 de março de 2018, a professora Gabriela está explicando aos alunos sobre as mudanças que as redes sociais trouxeram para a maneira de se comunicar e o quanto a interpretação de texto e o saber se comunicar ganham relevância na atualidade. No mesmo instante, ela percebe que os alunos mostram fotos em um aparelho de celular uns aos outros. São imagens íntimas da aluna Jade (Yara Charry), que se espalharam pela internet. A garota não está na sala de aula e Gabriela vai atrás dela pelas dependências da escola. Jade é encontrada escutando música sentada no parapeito da cobertura do colégio. Mesmo não sendo uma alusão a uma pretensão de suicídio por parte da adolescente, a cena cria uma dramaticidade que anuncia que a telenovela juvenil irá tratar de temas polêmicos e extremamente sérios na vida dos personagens da trama.

Durante a procura da professora pela aluna, diversos espaços do colégio são mostrados e, com isso, o telespectador já tem uma noção das ambientações que aparecerão na trama e do nível de excelência do próprio colégio. A trilha sonora é outro ponto pertinente, pois comunica movimento para a narrativa e introduz uma linguagem jovem e dinâmica.

Com o enquadramento de baixo para cima, a cena mostra as duas personagens com o sol as iluminando por trás e sugerindo que a professora é a luz que surgiu para iluminar a garota naquele momento, trazendo sábios conselhos para aliviar sua angústia. Jade, apesar de estar visivelmente envergonhada e chateada, recompõe-se da tristeza diante da atitude solidária da professora, que pega em suas mãos em um gesto de companheirismo e compreensão.

Esse tipo de cena, na qual é possível o telespectador se identificar com seus próprios dramas pessoais por meio das vivências dos personagens, é uma característica que fica evidente desde os primeiros momentos da telenovela. A verossimilhança como característica da construção narrativa é aqui exaltada nos diálogos e nas histórias contadas. O dinamismo das imagens é outra característica interessante, pois, principalmente nesse primeiro capítulo, temos várias tomadas externas que mostram a cidade e o colégio.

Percebe-se, portanto, a nítida tendência naturalista na narrativa e na estética de Malhação: Vidas Brasileiras, focada nas discussões de questões sociais e no dinamismo dos discursos narrativos que são comuns para muitos jovens na atualidade. O cotidiano desses garotos da ficção será um espelho para as questões pessoais dos jovens telespectadores. Rondelli ${ }^{16}$, apoiada nos estudos de Tomas Lopes Pumajero, observa que esse tipo de abordagem se tornou predominante em toda a produção ficcional televisiva brasileira e que isso 
"implica uma documentalidade e facilita processos de identificação e projeção ao mostrar situações extrapoláveis à cotidianidade do telespectador" ${ }^{17}$.

Outra questão relevante é que, quando há a discussão de temas sociais em telenovelas, esse diálogo se estende para diversas plataformas, tornam-se desde temas de conversação do cotidiano, perpassando fóruns de discussões em chats e redes sociais, até se tornarem pautas nas mídias tradicionais. O que é falado na telenovela é assunto também do dia a dia, o que pode gerar discussões em âmbito nacional, interferir no futuro da obra ou mudar pensamentos em relação a um determinado tema, além da evidente interferência cultural que isso proporciona. Portanto, citamos o fenômeno que Lopes ${ }^{18}$ identifica como "narrativa da nação" e destacamos sua importância como "recurso comunicativo", como observado em Malhação: Vidas Brasileiras:

Não resta dúvida de que a novela constitui um exemplo de narrativa que ultrapassou a dimensão do lazer, que impregna a rotina cotidiana da nação, construiu mecanismos de interatividade e uma dialética entre o tempo vivido e o tempo narrado e que se configura como uma experiência, ao mesmo tempo, cultural, estética e social. Como experiência de sociabilidade, ela aciona mecanismos de conversação, de compartilhamento e de participação imaginária. A novela tornou-se uma forma de narrativa da nação [...] e um modo de participar dessa nação imaginada. Os telespectadores se sentem participantes das novelas e mobilizam informações que circulam em torno deles no seu cotidiano. As relações do público com as novelas são mediadas por uma variedade de instituições, pesquisas de audiência, relações pessoais, contatos diretos com autores, além da imprensa e da mídia especializada e, mais recentemente, por dispositivos da internet ${ }^{19}$.

Provavelmente com a intenção de amenizar o clima, a cena que entra na sequência narra a brincadeira que a filha mais nova da professora Gabriela faz ao mudar o horário do despertador no celular da mãe, o que ocasiona o atraso dela para o trabalho e uma série de transtornos engraçados para a manhã da família. Além de apresentar a família da professora aos telespectadores - grupo que, obviamente, também acrescentará à trama problematizações a serem narradas -, esse expediente é o que Sadek ${ }^{20}$ define como "avalanche de fatos", outra característica comum às telenovelas, provavelmente herança das influências do melodrama neste tipo de ficção televisiva. Para o autor:

A 'avalanche de fatos' característica das telenovelas é mais importante que a qualidade dramática deles. A plateia brasileira se habituou a esse intenso número de ações. A avalanche de fatos é uma das características das narrativas mais modernas, dá ao público a sensação de movimento e atrai interesse pela história a que se assiste ${ }^{21}$.

Alguns recursos melodramáticos, mesmo nas telenovelas naturalistas, são preservados independentemente de qualquer predisposição contemporânea de fazer prevalecer a verossimilhança. Dos pontos importantes da matriz melodramática que prevalecem nas telenovelas brasileiras, ressalta-se que os "temas são inseparáveis das tramas românticas, dos enredos de família, do amor" e "é a lógica das relações pessoais e familiares que preside a narrativa dos problemas sociais" 22 .

17.Ibidem, p. 153

18.LOPES, 2014, op. cit.

19.Ibidem, p. 4

20.SADEK, José Roberto Telenovela: um olhar do cinema. São Paulo: Summus, 2008.

21.Ibidem, p. 79. 22.LOPES, 2009, op. cit., p. 27. 
Portanto, a conservação da matriz melodramática, típica das telenovelas brasileiras, não interfere na tendência observada a partir dos anos 1990 de trazer mais naturalismo e, consequentemente, mais realismo e verossimilhança para a telenovela.

\section{CONTAMINAÇÃO DE TEMAS}

Segundo Rondelli ${ }^{23}$, nas produções ficcionais da Rede Globo há um recorrente uso dos temas da realidade, como a crítica política, a responsabilidade com o meio ambiente, a intervenção social e a construção da cidadania. Em Malhação: Vidas Brasileiras, essa tendência é bem evidente já nesse primeiro capítulo, por exemplo, ao mostrar o drama vivido pela personagem Pérola (Rayssa Bratillieri), que é chamada na escola, pela mãe, para voltar para casa, pois seu pai, que é político, está sendo preso devido a uma acusação de corrupção ativa. A garota, além de ser zombada pelos colegas que recebem a notícia antes dela pela internet, tem de lidar com o peso dos acontecimentos e, ainda nesse capítulo de estreia, entra em surto depressivo, tomando remédios por conta própria e passando mal.

$\mathrm{Na}$ contemporaneidade, tem-se discutido sobre questões referentes à corrupção, devido ao cenário político brasileiro; e, particularmente, sobre o aumento dos casos de depressão, atingindo inclusive pessoas mais jovens. Esses temas cotidianos estão "contaminando" as narrativas ficcionais, como visto no primeiro capítulo; assim, abre-se o debate no âmbito do ficcional para que ele se espalhe no âmbito da realidade - ou vice-versa.

Essa "contaminação" aparece também na cena seguinte, na qual a professora Gabriela discute com o diretor da escola sobre sua intenção de sair de lá para participar do projeto da ONG Percurso, é também quando sua visita à sede da ONG é mostrada, junto de toda a aura de responsabilidade social que a cena apresenta. Isso se intensifica na cena da reunião que a professora tem com o conselho da escola, momento no qual sua sugestão de que a escola faça parceria com a ONG é rechaçada, e a professora faz um discurso emocionado sobre a necessidade de abraçarmos causas sociais para garantirmos um futuro mais digno para os jovens brasileiros carentes.

Essas três cenas, não obstante, também podem ser pensadas a partir do conceito de merchandising social, pois ultrapassam os temas das problemáticas pessoais e entram no campo das sociabilidades, da noção de coletivo, de comunidade e de cidadania, isto é, perpassam a noção de responsabilidade social. É sensato ressaltar que o enfoque do merchandising social necessita estar combinado com histórias em que prevaleça a verossimilhança, tendo em vista que, "ao propor ação pedagógica para uma possível mobilização social em torno de um tema, seja de saúde pública, ou mesmo de um comportamento moral, necessita de personagens que estejam vinculados ao mundo da realidade" ${ }^{24}$. 
A fusão entre a cena que mostra a professora Gabriela conversando com seu chefe no trabalho, o diretor Marcelo (Bukassa Kabengele), e, posteriormente, sua visita à ONG Percurso, apresenta imagens da personagem Talíssia (Luellem de Castro), embaladas por uma trilha musical, cuja letra diz: "Vim avisar que meu pai é Ogum - ogunhê! Minha mãe é Oxum - ora iê ô!", remetendo às entidades Ogum e Oxum (do candomblé) e anunciando, assim, outro tema que será abordado na telenovela mais à frente: a intolerância religiosa. Tal assunto também é amplamente discutido na sociedade, dada a própria característica inter-religiosa do Brasil e os conflitos por divergências religiosas espalhados pelo mundo.

Os temas polêmicos ecoam nas experiências íntimas dos telespectadores ${ }^{25}$, dessa forma, "os dramas ficcionais encontram sintonia com os dramas pessoais privados dos telespectadores" ${ }^{26}$. A telenovela Malhação: Vidas Brasileiras faz esse percurso explicitamente, trazendo para a casa do telespectador a discussão de temas que provavelmente fazem parte das suas próprias vivências e do cenário político e social no qual estão inseridos.

O entrelaçamento e o entrecruzamento de temas caracterizam a tendência naturalista da telenovela brasileira na contemporaneidade. Sua intenção de problematizar diferentes questões da atualidade, como a política, "instauram redes discursivas de debates nas quais múltiplas vozes e discursos que provêm da sociedade se entrecruzam e questionam estereótipos e estruturas culturais dominantes" 27 .

Assim, percebemos que Malhação: Vidas Brasileiras busca derrubar algumas barreiras discursivas e colocar em pauta diversos temas que irão impactar as discussões dos jovens telespectadores em seus cotidianos, de modo a criar uma narrativa cultural, além de direcionada para os adolescentes brasileiros, retroalimentada por eles mesmos. Temos, portanto, o fenômeno já observado por Lopes, característico das telenovelas brasileiras atuais: "uma estratégia de comunicabilidade à base da função da matriz melodramática com o tratamento realista e naturalista como fundamento da verossimilhança. E é essa estratégia híbrida de ficção e realidade que é advertida com intensidade ao longo da narrativa" ${ }^{28}$.

O capítulo termina com uma homenagem e um pedido dos alunos para que a professora Gabriela não se demita da escola e continue com eles. A letra da música que eles cantam para ela no restaurante de seu marido - "Por isso, não vá embora; por isso, não me deixe nunca mais... Vou morrer de saudades" imprime um desfecho melodramático a esse capítulo e uma linguagem mais juvenil para a assinatura da narrativa, duplamente reforçada pela ambientação dessa cena final e pela a trilha sonora pop, mas com uma tonalidade romântica.

\section{CONSIDERAÇÕES FINAIS}

Malhação: Vidas Brasileiras, enquanto temporada da soap opera Malhação, é inegavelmente uma narrativa midiática juvenil que contém potências comunicativas e
25.HAMBURGER, Esther Novela, política e intimidade: a construção da realidade. In: HAMBURGER Esther. O Brasil antenado: a sociedade da novela. Rio de Janeiro: Jorge Zahar 2005, p. 148-170.

26.MARQUES, Angela Cristina Salgueiro. Telenovela e política: perspectivas e modos de abordagem. Revista Significação, São Paulo, v. 42, n. 44, p. 318-338, 2015, p. 325.

27.Ibidem, p. 331.

28.LOPES, 2014, op. cit., p. 5. 
cargas culturais que merecem investigações pormenorizadas. Compreendida entre os anos de 2018 e 2019, os discursos que provêm da sociedade e que vão para as telas, ou o contrário, são visíveis já em seu primeiro capítulo, explicitando o enfoque em uma narrativa permeada pela exploração das questões sociais conectadas com o repertório cultural dos jovens telespectadores.

Em outras palavras, a tendência em privilegiar cenas do cotidiano e questões sociais permeadas pelos dramas familiares e histórias de amor não só confirmam que esse modo de se construir narrativas continua em voga, mas que é capaz de ser direcionado ao público mais jovem. Ainda que os telespectadores adolescentes estejam propensos a explorar narrativas mais inovadoras e/ou experimentais - pois já cresceram conectados às novas mídias e são mais exigentes em relação à introdução de novidades, quer sejam estéticas, quer sejam narrativas - a telenovela parece se manter como um produto midiático palatável a esse público.

Se a geração dos videogames e das redes sociais se interessa e acompanha a tradicional telenovela brasileira (principalmente em sua vertente mais naturalista), é porque a fórmula já está consagrada no imaginário e na cultura brasileira. Espera-se que este trabalho seja uma contribuição aos estudos televisivos que versam sobre esses aspectos e, com isso, deseja-se que as pesquisas acerca das narrativas midiáticas infantis e juvenis avancem no âmbito científico nacional.

\section{REFERÊNCIAS BIBLIOGRÁFICAS}

DESIDÉRIO, Plábio Marcos Martins. Merchandising social e os códigos da imagem televisiva: a construção de significados na telenovela. Revista GEMInIS, São Carlos, v. 1, n. 1, p. 82-98, 2010. Disponível em: http:/ /www.revistageminis. ufscar.br/index.php/geminis/article/view/10. Acesso em: $1^{\circ}$ maio 2019.

HAMBURGER, Esther. Novela, política e intimidade: a construção da realidade. In: HAMBURGER, Esther. O Brasil antenado: a sociedade da novela. Rio de Janeiro: Jorge Zahar, 2005. p. 148-170.

HERGESEL, João Paulo. Carrossel de sentimentos: melodrama na telenovela do SBT. Fronteiras: estudos midiáticos, São Leopoldo, v. 19, p. 72-82, 2017. Disponível em: http://www.revistas.unisinos.br/index.php/fronteiras/ article/view/12444. Acesso em: $1^{\circ}$ out. 2020.

HERGESEL, João Paulo; FERRARAZ, Rogério. Melodrama infantojuvenil na televisão brasileira: análise estilística de Carrossel (SBT, 2012-2013). Conexão: Comunicação e Cultura, Caxias do Sul, v. 16, n. 31, p. 201-222, 2017. Disponível em: http://www.ucs.br/etc/revistas/index.php/conexao/ article/view/5174. Acesso em: 18 abr. 2019. 
LOPES, Maria Immacolata Vassalo de. Telenovela como recurso comunicativo. MATRIZes, São Paulo, v. 3, n. 1, p. 21-47, 2009. Disponível em: http://www. revistas.usp.br/matrizes/article/view/38239. Acesso em: $1^{\circ}$ maio 2019.

LOPES, Maria Immacolata Vassalo de. Memória e identidade na telenovela brasileira. In: ENCONTRO ANUAL DA COMPÓS, 23., Universidade Federal do Pará, Curitiba, 2014. Anais [...]. Brasília: Compós, 2014. Disponível em: http://compos.org.br/encontro2014/anais/Docs/GT12_ESTUDOS_DE_ TELEVISAO/templatexxiiicompos_2278-1_2246.pdf. Acesso em: $1^{\circ}$ maio 2019.

MARQUES, Angela Cristina Salgueiro. Telenovela e política: perspectivas e modos de abordagem. Revista Significação, São Paulo, v. 42, n. 44, p. 318338, 2015. Disponível em: http://www.revistas.usp.br/significacao/article/ view/102506. Acesso em: $1^{\circ}$ maio 2019.

MARTÍN-BARBERO, Jesús. Latin America: cultures in the communication media. Journal of Communication, Oxford, v. 43, n. 2, p. 18-30, 1993. Disponível em: https:/ /academic.oup.com/joc/article-abstract/43/2/18/41 60017? redirectedFrom=fulltext. Acesso em: $1^{\circ}$ maio 2019.

MARTÍN-BARBERO, Jesús. Dos meios às mediações: comunicação, cultura e hegemonia. 2. ed. Rio de Janeiro: UFRJ, 2001.

RONDELLI, Elizabeth. Realidade e ficção no discurso televisivo. Letras, Curitiba, v. 11, n. 48, p. 149-207, 1997. Disponível em: https://revistas.ufpr. $\mathrm{br} /$ letras/article/view/19016/12326. Acesso em: $1^{\circ}$ maio 2019.

SADEK, José Roberto. Telenovela: um olhar do cinema. São Paulo: Summus, 2008.

THE INTERNATIONAL Format Awards. C21Media, Londres, 2019. Disponível em: https:/ / www.c21media.net/the-international-format-awards-2019/. Acesso em: $1^{\circ}$ maio 2019. 